\title{
Does prophylactic use of tranexamic acid reduce PPH from cesarean delivery when coupled with uterotonics?
}

$\overline{\text { FAST }}$

TRACK

Sentilhes and

colleagues

published the

largest prospective

study to date

addressing

the efficacy of

tranexamic acid

for the primary

prevention of $\mathrm{PPH}$

\begin{abstract}
Yes, there is a statistical effect, but the clinical implications are limited. In a randomized controlled trial involving 4,551 patients undergoing cesarean delivery (CD), women who received tranexamic acid in combination with prophylactic uterotonics had lower rates of postpartum hemorrhage (PPH) than women who received uterotonics and placebo. Clinically relevant hemorrhagerelated outcomes, such as blood transfusions and need for additional medications or procedures to control bleeding, did not differ between groups.
\end{abstract}

Sentilhes L, Senat MV, Le Lous M, et al; Groupe de Recherche en Obstetrique et Gynecologie. Tranexamic acid for the prevention of blood loss after cesarean delivery. $N$ Engl J Med. 2021;384:1623-1634. doi: 10.1056/NEJMoa2028788.

\section{EXPERT COMMENTARY}

Jonathan S. Hirshberg, MD, is Clinical Fellow in Maternal-Fetal Medicine and Surgical Critical Care, Washington University, St. Louis, Missouri.

Alison G. Cahill, MD, MSCI, is Professor, Maternal Fetal Medicine, Department of Women's Health, Dell Medical School/University of Texas at Austin.

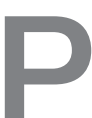

ostpartum hemorrhage is the leading cause of maternal mortality worldwide. ${ }^{1}$ Many preventive strategies, including tranexamic acid administration, have been studied in an attempt to reduce the risk of PPH. Tranexamic acid prevents the conversion of plasminogen to plasmin,

The authors report no financial relationships relevant to this article.

doi: 10.12788/obgm.0113 preventing the breakdown of fibrin, and ultimately stabilizing the fibrin matrix of clot. ${ }^{2}$ It has been shown to be an effective approach to treating hemorrhage in patients after trauma as well as cardiac surgery., ${ }^{3,4}$ The use of tranexamic acid in obstetric hemorrhage has reduced mortality in previous trials, ${ }^{5}$ but its prophylactic use has had mixed results in preventing obstetric hemorrhage..$^{6-8}$

Recently, Sentilhes and colleagues published the largest prospective study to date addressing the efficacy of tranexamic acid for the primary prevention of $\mathrm{PPH}$.

\section{Details of the study}

Multiple hospitals throughout France participated in the investigators' double-blind randomized, placebo-controlled trial. Women undergoing $\mathrm{CD}$ at 34 or more weeks' gestation $(\mathrm{N}=4,551)$ were randomly assigned to receive $1 \mathrm{~g}$ of intravenous (IV) tranexamic acid or placebo after cord clamping. Both groups received IV prophylactic uterotonics. 


\section{Examining the EVIDENCE}

CONTINUED FROM PAGE 16

\section{WHAT THIS EVIDENCE MEANS FOR PRACTICE}

Prevention of PPH would reduce the burden of maternal morbidity and mortality dramatically. Unfortunately, the addition of tranexamic acid as a prophylactic agent at CD does not appear to have a clinically significant impact on the outcomes that matter to patients or providers. While tranexamic acid certainly has a role in the treatment of $\mathrm{PPH}$, its benefit as a preventive agent has yet to be demonstrated.

JONATHAN S. HIRSHBERG, MD, AND ALISON G. CAHILL, MD, MSCI

The primary outcome was $\mathrm{PPH}$, defined by estimated blood loss (EBL) greater than $1 \mathrm{~L}$ or receipt of red blood cell transfusion within the first 2 days after surgery.

Results. The rate of $\mathrm{PPH}$ was significantly lower in women who received tranexamic acid compared with those who received placebo. Yet, the mean EBL between the 2 groups differed by only $100 \mathrm{~mL}$. The rates of blood transfusions, additional uterotonic administration, arterial embolization, and hysterectomy did not differ between groups.

The clinicians responsible for the care of these patients did not observe a difference in the rate of "clinically significant" $\mathrm{PPH}$ between those who received tranexamic acid and those who received placebo. Women who received tranexamic acid were more likely to experience nausea and vomiting, but they did not have any increased risk of venous thromboembolic disease.

\section{Study strengths and limitations}

Sentilhes and colleagues' study findings contradict those of an earlier meta-analysis on the topic. ${ }^{9}$ This may be due to the effect of publication bias on meta-analyses, which makes them prone to supporting the findings of published positive trials while missing data from negative trials that did not reach 
publication. The gold standard for addressing a research question such as this is a randomized controlled trial (RCT). The study reviewed here is an excellent example of a well-designed and executed RCT.

There may be a benefit to prophylactic tranexamic acid in certain populations not well captured among these study participants. The inclusion criteria were broad, including both prelabor and intrapartum CDs, making the results generalizable. However, the population studied, with a mean body mass index of $26 \mathrm{~kg} / \mathrm{m}^{2}$ and age of 33 , may not resemble some readers' patient population. Prespecified subgroup analyses did not find a benefit to tranexamic acid in patients considered at high risk for PPH or in those undergoing intrapartum CD.

\section{References}

1. Say L, Chou D, Gemmill A, et al. Global causes of maternal death: a WHO systematic analysis. Lancet Glob Health. 2014;2:e323-e333.

2. Chauncey JM, Wieters JS. Tranexamic Acid. StatPearls Publishing LLC [internet]; 2021.

3. Karski JM, Teasdale SJ, Norman P, et al. Prevention of bleeding after cardiopulmonary bypass with high-dose tranexamic acid. Double-blind, randomized clinical trial. $J$ Thorac Cardiovasc Surg. 1995;110:835-842.

4. Roberts I, Shakur H, Coats T, et al. The CRASH-2 trial: a randomised controlled trial and economic evaluation of the effects of tranexamic acid on death, vascular occlusive events and transfusion requirement in bleeding trauma patients. Health Technol Assess. 2013;17:1-79.

5. WOMAN Trial Collaborators. Effect of early tranexamic acid administration on mortality, hysterectomy, and other morbidities in women with post-partum haemorrhage

(WOMAN): an international, randomised, double-blind, placebo-controlled trial. Lancet. 2017;389:2105-2116.

6. Sentilhes L, Winer N, Azria E, et al; Groupe de Recherche en Obstetrique et Gynecologie. Tranexamic acid for the prevention of blood loss after vaginal delivery. $N$ Engl J Med. 2018;379:731-742.

7. Shahid A, Khan A. Tranexamic acid in decreasing blood loss during and after caesarean section. J Coll Physicians Surg Pak. 2013;23;459-462.

8. Simonazzi G, Bisulli M, Saccone G, et al. Tranexamic acid for preventing postpartum blood loss after cesarean delivery: a systematic review and meta-analysis of randomized controlled trials. Acta Obstet Gynecol Scand. 2016;95:28-37.

9. Wang Y, Liu S, He L. Prophylactic use of tranexamic acid reduces blood loss and transfusion requirements in patients undergoing cesarean section: a meta-analysis. J Obstet Gynaecol Res. 2019;45:1562-1575. 